\title{
Recreational Use of "Ecstasy" (MDMA) Is Associated with Elevated Impulsivity
}

\author{
Michael J. Morgan, Ph.D.
}

Recent preclinical evidence suggests that repeated exposure to 3, 4-methylenedioxy-methamphetamine (MDMA; "ecstasy") produces long-term reductions in serotonin (5HT) levels. 5-HT has been implicated in the regulation of mood, anxiety, aggression, impulsivity, and cognition. Accordingly, in the first of two separate studies, these variables were investigated in three groups: (1) MDMA group - recreational ecstasy users (who also used other illicit substances); (2) polydrug controls - who had never taken ecstasy, but otherwise had drug histories and personal characteristics similar to the ecstasy users; and (3) nondrug controls-who had never used illicit drugs, but had similar personal characteristics. All participants completed mood (Likert) scales, personality questionnaires (which included the impulsiveness, venturesomeness and empathy questionnaire-IVE), spatial span and "Tower of London" (TOL) tests, and a behavioural measure of impulsivity, the matching familiar figures test (MFF20). There were no group differences in mood, anxiety, anger/hostility, and cognitive performance, but the MDMA group committed significantly more errors in the MFF20. Subsequently, a larger sample of participants were administered mood (the General Health Questionnaire or GHQ) and personality (IVE) questionnaires before the administration of a TOL test, followed by the MFF20, and a second TOL test. Although there were no group differences in TOL performance, ecstasy users were again found to commit more errors in the MFF20 than polydrug users.

Furthermore, the GHQ and IVE scores of the ecstasy users in the second study indicated, respectively, that they were more psychologically disturbed and impulsive than nondrug controls. The combined data from the two studies indicated that ecstasy users exhibited elevated impulsivity on both self-report and behavioral measures and that those who had taken the most ecstasy had the most elevated trait impulsiveness scores. These findings are consistent with previous evidence that elevated levels of impulsivity in humans are associated with reduced levels of serotonergic function. [Neuropsychopharmacology 19:252-264, 1998] (C) 1998 American College of Neuropsychopharmacology. Published by Elsevier Science Inc.
KEY WORDS: MDMA, Serotonin; Neurotoxicity; Impulsivity

Considerable preclinical evidence has accumulated that "ecstasy" (3, 4-methylenedioxymethamphetamine or MDMA)

From the Department of Psychology, University of Wales, Swansea, S. Wales, UK.

Address correspondence to: Dr. M.J. Morgan, Centre for Substance Abuse Research, Department of Psychology, University of Wales Swansea, Singleton Park, Swansea, SA2 8PP, S. Wales, UK.

Received December 31, 1996; revised December 22, 1997; accepted January 21, 1998. causes long-term decreases in brain 5-HT and 5-HIAA concentrations and suspected 5-HT axon terminal degeneration in a variety of animal species (for reviews, see McKenna and Peroutka 1990; Steele et al. 1994; Green et al. 1995; Frederick and Paule 1997). Recent evidence from studies with human participants is consistent with these findings. Recreational ecstasy users have been reported to exhibit significantly lower CSF 5-HIAA levels (Ricaurte et al. 1990; McCann et al. 1994), and in a recent PET study, ecstasy users were found to have reduced 5-HT transporter binding in all brain regions, as compared to ecstasy-naive controls (Szabo et al. 1997). 
Serotonin has been implicated in the regulation of mood, anxiety, aggression, and impulsivity. Transient reductions in 5-HT activity, induced by tryptophan depletion, have been reported to produce a rapid lowering of mood in normal males (Young et al. 1985; Smith et al. 1987) and relapse in recently remitted depressed patients (Delgado et al. 1990). Furthermore, there is evidence that disorders of central serotonergic neurotransmission, as reflected by low levels of 5-HIAA, are associated with anxiety (e.g., Garvey et al. 1995), impulsive and aggressive personality traits (e.g., Linnoila et al. 1993), and suicidal behavior (Traskman-Bendz et al. 1986). It has also been proposed that 5-HT may play an orchestrating role in cognition, and that extreme deviations of 5-HT activity can result in biases in cognitive processing (Spoont 1992) and impairments in learning and memory (e.g., Hunter 1988).

Despite this evidence, the possible long-term psychological sequelae of ecstasy use in humans has received relatively little attention from researchers, partly because most controlled laboratory studies of the effects of repeated administration of ecstasy are precluded for legal and ethical reasons. Nevertheless, preliminary evidence has emerged that recreational use of ecstasy may, indeed, be associated with differences in psychological measures. In addition to significantly lower levels of CSF 5-HIAA, Ricaurte et al. (1990) reported that their sample of 30 recreational ecstasy users exhibited lower scores on personality measures of impulsivity and indirect hostility (McCann et al. 1994). There are also reports that recreational ecstasy users exhibited significant decrements in working memory in ecstasy users, as compared with alcohol users (Curran and Travill 1997), and were impaired on tests of immediate and delayed recall, as compared to nonusers, although they were unimpaired on other neuropsychological tests (Krystal and Price 1992; Parrott 1997).

One of the problems encountered with investigation of the potential effects of MDMA in humans, however, is that the majority of recreational ecstasy users also use many other illicit drugs. All previous investigations of the psychological sequelae of recreational ecstasy use have failed to control adequately for the possible longterm influence of other illicit, and legal (e.g., alcohol), drugs on behavior. A strategy that can be adopted to identify the psychological sequelae associated with ecstasy use specifically, as distinct from those associated with the use of illicit drugs generally, is to compare the performance of ecstasy users not only with that of participants who have never taken any illicit drugs, but also with a group of polydrug users, who have used similar amounts of other illicit drugs, but have never taken ecstasy. The first of the present studies employed this design to determine if a history of recreational ecstasy use is specifically associated with functional domains in which 5-HT has been implicated, including: mood, anxiety, anger/hostility, impulsivity, and cognitive performance.

The results of the first study indicated that ecstasyusers committed significantly more errors in a behavioral test of impulsivity, but there were few other significant differences between the ecstasy users and participants in the other two groups. In light of the potential theoretical implications of the evidence for elevated behavioral impulsivity in the first study, another, larger, sample of participants was recruited, and a second study was conducted to determine the reliability of this finding. Finally, because both studies employed the same design, the data from measures that were common to both were combined for further analysis.

\section{METHODS (STUDY 1)}

\section{Participants}

Forty-four participants participated in the first study: 16 recreational ecstasy users (MDMA group), 12 polydrug controls, and 16 nondrug controls. The demographics of the study groups are shown in Table 1. All participants were university students or graduates who were recruited by poster advertisements and word of mouth and were first screened for eligibility by interviews. For inclusion in the MDMA group, individuals had to be in good health, to have used ecstasy on at least 20 occasions, and could not have any of the exclusionary criteria (see below). To be admitted to the polydrug control group, participants had to meet all of these criteria, and have a drug-use history that was similar to that of the MDMA participants, with the exception being that they must have no history of ecstasy exposure. To be in the nondrug control group, participants had to meet the same personal characteristics criteria, and have no history of use of illicit drugs.

Information about past use of ecstasy was obtained in several ways: (1) a preliminary telephone or face-to-face interview; (2) a general drug-use questionnaire; and (3) a specific ecstasy-use questionnaire that requested information on the duration of usage, the last time used, the amount (number of tablets) used in the last month, the frequency of use per month, the average amount taken per session, the maximum amount taken per session, and the total amount taken in the participant's lifetime.

Exclusionary criteria for all groups included past or present major illnesses, pregnancy, history of psychosis, current major depressive disorder, and alcohol or opiate dependence. Participants who passed the initial screening were administered the National Adult Reading Test (NART) (Nelson 1982) to ensure an adequate knowledge of English (they were required to score fewer than 25 incorrect answers to participate), and to provide an estimate of premorbid IQ. The study was approved by the local health authority ethics committee. 
Table 1. Means (Standard Deviations) for Personal Characteristics (Study 1)

\begin{tabular}{lccr}
\hline & & Polydrug & \\
& Nondrug Control $(\boldsymbol{N}=\mathbf{1 6})$ & Control $(\boldsymbol{N}=\mathbf{1 2})$ & MDMA (N= 16) \\
\hline Age & $21.87(6.09)$ & $20.25(1.48)$ & $20.94(1.88)$ \\
Gender $^{a}$ & $1.62(0.50)$ & $1.42(0.51)$ & $1.50(0.52)$ \\
Height, $\mathrm{cm}$ & $171.3(9.99)$ & $172.3(7.65)$ & $170.0(10.0)$ \\
Weight, $\mathrm{kg}_{\text {Education }^{b}}$ & $69.15(12.91)$ & $62.22(7.18)$ & $61.26(9.63)$ \\
Est. IQ $^{c}$ & $2.69(0.60)$ & $2.67(0.49)$ & $2.94(0.25)$ \\
\hline
\end{tabular}

\footnotetext{
${ }^{a}$ Males coded as 1 ; females as 2 .

${ }^{b} 1=$ GCSE, $2=$ A-level, $3=$ HND.+

${ }^{c}$ Estimated from NART scores.
}

\section{Psychological Measures}

Mood Scales. All participants were administered a current mood questionnaire which comprised nine 6-point Likert scale items (happy, depressed/blue, joyful, unhappy, pleased, enjoyment/fun, frustrated, worried/ anxious, angry/hostile) with a rating of 0 indicating "not at all," and a rating of 6 indicating "extremely."

Questionnaire Measures. All participants were also administered the State-Trait Anxiety Inventory (STAI) (Spielberger et al. 1983), the State-Trait Anger Expression Inventory (STAXI, Spielberger 1988), and the Impulsiveness, Venturesomeness, and Empathy scale (IVE) (Eysenck and Eysenck 1991). The IVE yields three independent scores for impulsiveness, venturesomeness, and empathy, which range from 0 to 19 for impulsiveness and empathy, and from 0 to 16 for venturesomeness. High scores indicated high levels of these personality characteristics. The STAI produces a score for state and trait anxiety levels, which ranges from 20 to 80 in both cases. Low scores indicated low anxiety levels. The STAXI yields state (S-Anger), and trait (T-Anger), anger/hostility scores that were converted into $t$-scores based on normalized linear transformations, according to the STAXI professional manual. High scores indicated elevated levels of anger/hostility.

\section{CANTAB Measures.}

TOWER OF LONDON. Cognitive functioning was investigated with the use of the Cambridge Neuropsychological Test Automated Battery (CANTAB), Working Memory and Planning Battery: a suite of computerized tests, employing a touch-sensitive screen, which has been used to examine differential patterns of cognitive deficits in frontal lobe patients (e.g., Owen et al. 1990). Participants were administered the CANTAB "Tower of London" (TOL) test, a test of planning that taxes central executive function and is based on the test developed by Shallice and McCarthy (Shallice 1982). Participants were required to compare two different arrangements of different colored "balls" in "pockets" (one on the top half of the screen and one on the bottom half) and to re- arrange the balls in the lower half of the screen so that their positions match the "goal" arrangement in the upper half screen, in the minimum number of moves. After six practice trials, there were $2,3,4$, and 5 move problems, which demanded that participants plan the solution to the problem prior to the first move. The number of moves required by the participant to rearrange the balls correctly and the selection and movement latencies for both the first and subsequent moves were recorded. A "yoked control" condition for each test condition was employed to provide baseline measures of motor initiation and execution times in milliseconds. In this condition, the solutions the participant had generated previously, for the 2, 3, 4, and 5 move problems, were played back, one move at a time, and the participant simply had to follow these movements. Several measures were recorded: "number of excess moves" refers to the number of moves above the minimum possible that were required to complete a particular solution; "proportion of perfect solutions" refers to the proportion of total problems that were solved in the minimum possible number of moves; "initial thinking time" refers to the time between presentation of the problem and the first touch of the screen; and "subsequent thinking time per move" refers to the time between the first move of the solution and the completion of the problem, divided by the number of moves taken for that problem. For both initial and subsequent thinking times, simple movement times, derived from the yoked control condition, were subtracted from the total thinking times to provide an accurate estimate of pure planning time, unconfounded by any motor deficits. Specifically, "motor initiation" times were subtracted from the initial thinking times, and "motor execution" times were subtracted from the subsequent thinking times.

SPATIAL SPAN. Participants were also administered the Spatial Span (Span) test, from the CANTAB Working Memory and Planning Battery, to investigate the "visuo-spatial sketchpad" component of Baddeley's theory of working memory (Baddeley, 1990). A pattern of white squares was shown on the touch-screen. Some 
of the squares changed color, one-by-one, in a variable sequence. At the end of the presentation, a tone indicated that the participant should touch each of the squares that changed color in the same sequence as they were presented. The task became progressively more difficult, as the number of squares in the sequence was increased from two, at the start of the test, to a maximum of nine. There were three sequences at each level of difficulty. If the participant was unable to repeat all sequences at any one level, the three sequences at the next level were presented, but then the test was terminated. Participants were given one practice trial before commencing at the two-square level. Three dependent variables were derived: spatial span (highest possible span $=9$ ), number of sequence errors made, and the number of usage errors made (the number of times a box was pressed that was not illuminated during the task). The sequence of administration of the TOL and Span tests were counterbalanced to avoid order effects.

Matching FAmiliar Figures Test. Finally, participants were administered a behavioral measure of impulsivity-the 20 item Matching Familiar Figures Test (MFF20), which was derived from the original Matching Familiar Figures Test (Kagan et al. 1964), by Cairns and Cammock (1978). The test format of the MFF20, involves simultaneous presentation of a stimulus figure and an array of six alternatives, all except one of which differ one or more details. The subject was then asked to select from the alternatives the figure that exactly matched the standard. Each subject was given two practice items followed by 20 test items. If their initial selection was incorrect, they were told that they were wrong and were asked to try again. For each subject, the 20 items were scored according to the time to first response, the first position indicated, and the number of errors made before the correct match. Three dependent variables were analyzed: (1) the mean latency to first response; (2) the total number of errors committed; and (3) an "I score" — a composite index of impulsivity, originally derived by Salkind and Wright (1977) and validated by Messer and Brodzinsky (1981), which was calculated by subtracting the standard score of the mean latency to first response from the standard score of the total number of errors committed $\left(Z_{e}-Z_{1}\right)$.

Statistical Analyses. The data were analysed using multivariate analysis of variance, and Duncan's multiple range test was employed for post hoc analyses.

\section{RESULTS (STUDY 1)}

\section{Personal Characteristics and Drug Histories}

Multivariate analysis of variance (MANOVA) of the personal characteristics of participants in the three experimental groups (MDMA, polydrug control, and non- drug control) indicated that they were not significantly different in terms of their age, gender ratio, education level achieved, height, weight, or estimated premorbid IQ (see Table 1). Furthermore, analysis of self-reported drug use histories of participants in the two polydrugusing groups (MDMA and polydrug controls) showed that their duration of use of alcohol, cannabis, and amphetamine was not significantly different, nor was their consumption of cigarettes in the week prior to testing, alcohol and cannabis in the previous month, or amphetamine in the previous year (see Table 2). Self-reported use of other classes of illicit drugs was not sufficiently frequent for comparison with parametric statistics. However, the drug histories of the two groups seemed similar in terms of use of LSD, pscilocybin mushrooms, and benzodiazepines. Eleven of the 16 MDMA participants, and seven of the 12 polydrug control participants reported occasional use of LSD. Six of the MDMA participants and seven of the polydrug control participants reported occasional use of psilocybin mushrooms. Three of MDMA participants and two of the polydrug control participants reported occasional use of benzodiazepines. The groups did differ with respect to their (infrequent) use of cocaine, amylnitrite, and barbiturates. Six of the MDMA participants reported having used cocaine but only on one occasion, and more than a month prior to testing, in all cases. Three of the MDMA participants reported occasional use of amylnitrate ("poppers") more than 2 months prior to testing. One polydrug control subject reported once having used an unknown barbiturate. Finally, one of the nondrug control participants admitted to having used cannabis on one occasion several years before testing.

\section{MDMA Use}

Characteristics of self-reported MDMA use among the 16 participants in the MDMA group are summarized in Table 3. Seven of these participants reported that they

Table 2. Means (Standard Deviations) for Self-Reported Drug Consumption (Study 1)

\begin{tabular}{lcr}
\hline & Polydrug Control & MDMA Group \\
\hline Alcohol (units) & & \\
$\quad$ Consumed per month & $85.67(54.7)$ & $67.12(52.0)$ \\
$\quad$ Duration of use (years) & $7.25(2.49)$ & $8.31(3.00)$ \\
Cigarettes & & \\
$\quad$ Smoked per week & $71.67(73.3)$ & $64.81(59.9)$ \\
Cannabis (joints) & & \\
$\quad$ Smoked per month & $50.5(42.1)$ & $59.75(42.4)$ \\
$\quad$ Duration of use (years) & $4.67(1.56)$ & $5.69(1.89)$ \\
Amphetamine (grams) & & \\
$\quad$ Comsumed per year & $19.2(21.1)$ & $17.2(15.0)$ \\
$\quad$ Duration of use (years) & $2.42(1.56)$ & $2.56(1.97)$ \\
LSD ("trips”) & & \\
$\quad$ Consumed per year & $18.33(37.25)$ & $6.19(11.93)$ \\
\hline
\end{tabular}


Table 3. Means (Standard Deviations) for Self-Reported Ecstasy Use (Studies 1 and 2)

\begin{tabular}{lcc}
\hline & Study $\mathbf{1}(\mathbf{N}=\mathbf{1 6})$ & Study $\mathbf{2}(\mathbf{N}=\mathbf{2 5})$ \\
\hline Number of male participants & 8 & 13 \\
Number of female participants & 8 & 12 \\
Period since last use, days & $20.4(33.6)$ & $65.1(85.7)$ \\
Duration of use, years & $2.12(1.36)$ & $4.12(1.27)$ \\
Frequency of use per month & $2.94(0.93)$ & $4.36(1.15)$ \\
Average amount used per session, tablets & $1.12(0.34)$ & $1.47(0.78)$ \\
Maximum amont used per session, tablets & $2.28(1.25)$ & $3.78(2.17)$ \\
Estimated total lifetime usage, tablets & $35.6(17.5)$ & $49.6(33.2)$ \\
\hline
\end{tabular}

had taken ecstasy within the week before to testing, although none had taken it for at least 3 days prior to testing. The number of participants who reported longterm psychological problems they attributed to their use of ecstasy is summarized in Table 4.

\section{Questionnaire Measures}

Multivariate analysis of variance of the Likert scale items: happy, depressed/blue, joyful, unhappy, pleased, enjoyment/fun, frustrated, worried/anxious, angry/ hostile indicated that there were no significant differences between groups (MDMA, polydrug control, and nondrug control) for any of these mood states at the time of testing. Similarly, analysis of state and trait anxiety, and anger/hostility, measures derived from the STAI and STAXI, respectively, indicated that there were no significant differences between the groups in terms of these measures of anxiety and anger. Finally, analysis of the scores on the impulsiveness, and empathy, subscales of the IVE, indicated that there were no significant differences between the groups in terms of these trait measures. There was, however, a significant difference between scores on the venturesomeness subscale $[\mathrm{F}(2,41)=5.896, p=.006]$. Post hoc analysis with Duncan's test indicated that this difference was attributable to the elevated levels of trait venturesomeness of partic- ipants in the two illicit drug-using groups, as compared to those in the nondrug using control group (see Table 5).

\section{Behavioral Measures}

Multivariate analysis of variance of spatial span, total number of sequence errors made, and total number of usage errors made (the number of times a box was pressed that was not illuminated during the spatial span task) indicated that participants in the three experimental groups (MDMA, polydrug control, and nondrug control) were not significantly different in terms of any of these measures of spatial span performance. Similarly, analysis of the "number of excess moves," "proportion of perfect solutions," "initial thinking time," and "subsequent thinking time per move" measures of TOL performance indicated that there were no significant differences between groups for any of these measures (see Table 6).

Finally, analysis of the measures of MFF20 performance indicated that there were no group differences in the mean latencies to first response, but there was a highly significant difference between groups in the total number of errors committed [F $(2,41)=9.072, p=.001]$, and the derived "I scores" [F $(2,41)=5.103, p=.010]$. Post hoc analysis with Duncan's test indicated that this effect was attributable to the fact that participants in the

Table 4. Number of Participants Reporting Various Long-Term Side-Effects of Ecstasy (Studies 1 and 2)

\begin{tabular}{lcc}
\hline & Study $\mathbf{1}(\mathbf{N}=\mathbf{1 6})$ & Study $\mathbf{2}(\mathbf{N}=\mathbf{2 5})$ \\
\hline More susceptible to anxiety & $5(1 \mathrm{M}, 4 \mathrm{~F})$ & $12(7 \mathrm{M}, 5 \mathrm{~F})$ \\
More susceptible to depression & $3(1 \mathrm{M}, 2 \mathrm{~F})$ & $7(2 \mathrm{M}, 5 \mathrm{~F})$ \\
More aggressive/irritable & $4(2 \mathrm{M}, 2 \mathrm{~F})$ & $6(5 \mathrm{M}, 1 \mathrm{~F})$ \\
Mood swings & $4(0 \mathrm{M}, 4 \mathrm{~F})$ & $6(5 \mathrm{M}, 1 \mathrm{~F})$ \\
Loss of appetite & $3(1 \mathrm{M}, 2 \mathrm{~F})$ & $6(3 \mathrm{M}, 3 \mathrm{~F})$ \\
Sleep problems & $2(1 \mathrm{M}, 1 \mathrm{~F})$ & $5(1 \mathrm{M}, 4 \mathrm{~F})$ \\
Reduced ability to concentrate & $6(1 \mathrm{M}, 5 \mathrm{~F})$ & $4(1 \mathrm{M}, 3 \mathrm{~F})$ \\
Impaired memory & $1(0 \mathrm{M}, 1 \mathrm{~F})$ & $4(2 \mathrm{M}, 2 \mathrm{~F})$ \\
Mental slowness & $2(1 \mathrm{M}, 1 \mathrm{~F})$ & $3(1 \mathrm{M}, 2 \mathrm{~F})$ \\
Paranoia & $0(0 \mathrm{M}, 0 \mathrm{~F})$ & $2(1 \mathrm{M}, 1 \mathrm{~F})$ \\
Total & $10(4 \mathrm{M}, 6 \mathrm{~F})$ & $21(11 \mathrm{M}, 10 \mathrm{~F})$ \\
\hline
\end{tabular}


Table 5. Means (Standard Deviations) for Questionnaire Measures

\begin{tabular}{lccc}
\hline & $\begin{array}{c}\text { Nondrug } \\
\text { Control }(\mathbf{N}=\mathbf{1 6})\end{array}$ & $\begin{array}{c}\text { Polydrug } \\
\text { Control }(\mathbf{N}=\mathbf{1 2})\end{array}$ & MDMA (N= 16) \\
\hline Mood & & & \\
Happy & $3.19(1.60)$ & $3.25(0.87)$ & $3.19(0.91)$ \\
Depressed/blue & $0.81(1.11)$ & $0.92(1.62)$ & $0.75(0.93)$ \\
Joyful & $2.50(1.71)$ & $2.33(1.23)$ & $2.44(1.41)$ \\
Unhappy/sad & $0.62(0.81)$ & $0.58(1.00)$ & $0.56(0.81)$ \\
Pleased & $2.50(1.67)$ & $2.50(1.00)$ & $2.62(1.15)$ \\
Enjoyment/fun & $2.81(1.97)$ & $2.92(1.31)$ & $2.62(1.45)$ \\
Frustrated & $1.25(1.48)$ & $1.25(1.66)$ & $1.19(1.47)$ \\
Worried/anxious & $1.94(1.44)$ & $1.42(1.56)$ & $0.12(1.17)$ \\
Angry/hostile & $0.44(1.26)$ & $0.33(0.89)$ & \\
Personality & & & $34.31(8.01)$ \\
State anxiety & $39.31(12.28)$ & $39.33(13.97)$ & $38.68(10.84)$ \\
Trait anxiety & $39.06(8.82)$ & $41.41(8.72)$ & $10.50(4.47)$ \\
Impulsiveness & $8.56(4.59)$ & $9.75(3.89)$ & $13.75(5.00)$ \\
Venturesomeness & $7.25(3.49)$ & $11.17(4.47)$ & $51.00(4.26)$ \\
Empathy & $13.37(4.47)$ & $14.75(3.49)$ & $52.69(9.46)$ \\
State anger & $50.56(5.02)$ & $51.33(5.84)$ & \\
Trait anger & $49.06(9.36)$ & $51.67(7.76)$ & \\
\hline
\end{tabular}

${ }^{a}$ Significant difference between groups at the .05 probability level.

MDMA group committed more than twice as many errors in the MFF20 task than participants in the other two control groups (see Table 6).

\section{STUDY 2}

Limitations with the previous study included: small sample sizes, lack of information about the type of ecstasy tablets taken, and the fact that seven of the 16 participants in the MDMA group reported that they had taken ecstasy within the week prior to testing, although none reported having had taken any for at least 3 days prior to testing. The present study sought to address these limitations by recruiting a larger sample of participants for each group, with more MDMA participants who had not taken ecstasy for several weeks, and asking participants to identify the total number of each type of ecstasy tablet that they had taken. Because the questionnaire measures of mood state, and state- and trait-anxiety, and anger/hostility employed in the previous study had failed to differentiate between groups in both that study and earlier ones (Callow 1996; Davies 1996), these measures were replaced by a single ques-

Table 6. Means (Standard Deviations) for Behavioral Measures

\begin{tabular}{lccc}
\hline & $\begin{array}{c}\text { Nondrug } \\
\text { Control }(\mathbf{N}=\mathbf{1 6})\end{array}$ & $\begin{array}{c}\text { Polydrug } \\
\text { Control ( }=\mathbf{1 2})\end{array}$ & MDMA (N= 16) \\
\hline Spatial span & & & \\
$\quad$ Span & $6.69(1.35)$ & $6.00(1.41)$ & $6.87(1.02)$ \\
$\quad$ Total errors & $11.87(6.00)$ & $14.75(5.95)$ & $13.25(4.95)$ \\
$\quad$ Usage errors & $1.81(1.11)$ & $2.17(1.75)$ & $2.37(2.39)$ \\
Tower of London & & & \\
$\quad$ Excess moves per problem & $1.27(0.64)$ & $1.42(0.74)$ & $1.52(0.88)$ \\
$\quad$ Proportion perfect solutions & $61.46(15.78)$ & $61.11(18.91)$ & $59.06(19.99)$ \\
$\quad$ Initial thinking time, ms & $3688(3047)$ & $4668(3686)$ & $3434(2106)$ \\
$\quad$ Subsequent thinking time, & & & \\
$\quad$ ms per move & $1070(802)$ & $1541(1510)$ & $1561(1335)$ \\
Matching familiar figures test & & & \\
$\quad$ Latency to first response & $16.19(5.83)$ & $14.73(5.27)$ & $12.48(6.64)$ \\
$\quad$ Total errors committed & $5.18(3.10)$ & $4.83(2.25)$ & $11.81(7.57)^{a}$ \\
“I score" & $-0.67(1.28)$ & $-0.49(1.16)$ & $1.04(2.19)^{b}$ \\
\hline
\end{tabular}

${ }^{a}$ Significant difference between groups at the .001 probability level.

${ }^{b}$ Significant difference between groups at the .01 probability level. 
tionnaire measure of current psychological health status, the 12-item General Health Questionnaire (GHQ) (Goldberg 1978). The IVE was retained, because it had diffferentiated between groups in both the previous study and an earlier investigation (Callow).

A similar policy was adopted toward the behavioral measures employed in the previous study. The CANTAB spatial span test was dispensed with, and the TOL was retained and repeated on two successive occasions to explore the possibility that it might differentiate between groups more effectively once participants had become familiar with the task. Finally, the MFF20 test was administered again, interposed between the two TOL tests.

There was one other innovation in the present study. Before the administration of the first TOL test, participants were presented with a brief audiotaped news story taken from the Rivermead Behavioral Memory Test (Wilson et al. 1985) and were then tested for immediate recall. They were subsequently tested for delayed recall after completion of the second TOL test. The results of the latter test have been submitted for publication elsewhere.

\section{METHODS (STUDY 2)}

\section{Participants}

Sixty-four participants participated in the second study: 25 ecstasy users (MDMA group), 20 polydrug controls; and 19 nondrug controls. The demographics of the study groups are shown in Table 4 . Again, all participants were university students or graduates who were recruited by poster advertisements and word of mouth. All participants were first screened for eligibility by interviews using the criteria employed in the first study. In addition to obtaining information about past ecstasy consumption through the use of an interview and a questionnaire, participants were also requested to identify the number of each type of tablet they had ever taken with the aid of a list of available "brands." Four participants were excluded from the study: two polydrug controls because of exceptionally high NART scores; one MDMA participant who was taking antidepressant medication, and one nondrug control because of recent alcohol intoxication.

\section{Psychological Measures}

On the test day, participants were administered the 12item GHQ and the IVE. They were then instructed to listen to a brief audiotaped news story taken from the Rivermead Behavioral Memory Test (RBMT) and were tested for immediate recall. The participants then completed two successive TOL tests and an intervening MFF20 test. After they had completed these tests, 40-50 min after the story had been presented, subjects were tested for delayed recall. Again, MANOVA was used to compare the data from the three experimental groups, and Duncan's multiple range test was employed for post hoc analyses. The Pearson product-moment correlation coefficient was used as a measure of correlation.

\section{RESULTS (STUDY 2)}

\section{Personal Characteristics and Drug Histories}

Multivariate analysis of variance of the personal characteristics of participants in the three experimental groups (MDMA, polydrug control, and nondrug control) indicated that they were not significantly different in terms of their age, gender ratio, education level achieved, height, weight, or estimated premorbid IQ (see Table 7). Furthermore, analysis of self-reported drug use histories of participants in the two polydrug-using groups (MDMA and polydrug controls) showed that they were not significantly different in terms of their duration of use of alcohol, cigarettes, cannabis, amphetamine, and LSD. Generally, there were also no group differences in estimated total consumption of: alcohol, cigarettes, and cannabis per week; amphetamine and inhalants ("poppers") per month, or cocaine, LSD, and psilocybin mushrooms in the previous year (see Table 8). In the MDMA group, however, eight participants reported occasional use of benzodiazepines, three reported having used barbiturates, and two reported having taken ketamine; whereas, none of the participants in the polydrug control group reported having used these drugs.

\section{MDMA Use}

Characteristics of self-reported MDMA use among the 25 participants in the MDMA group are summarized in Table 3. Five of these participants reported that they had last taken ecstasy within the week prior to testing, although none had taken it for at least 3 days prior to testing. The number of participants who reported longterm psychological problems which they attributed to their use of ecstasy is summarized in Table 4.

\section{Questionnaire Measures}

The IVE trait empathy scores were not significantly different between the three groups, but there were significant differences in their trait impulsiveness $[\mathrm{F}(2,61)=$ $3.274, p=.045]$, venturesomeness $[\mathrm{F}(2,61)=4.508, p=$ $.015]$, and GHQ [F $(2,61)=4.303, p=.018]$, scores. Post hoc analysis with Duncan's test indicated that participants in the MDMA group exhibited significantly higher levels of trait impulsiveness and venturesomeness and significantly lower GHQ scores than participants in the nondrug control group. However, MDMA 
Table 7. Means (Standard Deviations) for Personal Characteristics (Study 2)

\begin{tabular}{lccc}
\hline & $\begin{array}{c}\text { Nondrug } \\
\text { Control }(\boldsymbol{N}=\mathbf{1 9})\end{array}$ & $\begin{array}{c}\text { Polydrug } \\
\text { Control }(\boldsymbol{N}=\mathbf{2 0})\end{array}$ & MDMA (N= 25) \\
\hline Age & $21.74(2.94)$ & $23.00(4.71)$ & $22.28(2.48)$ \\
Gender $^{a}$ & $1.63(0.50)$ & $1.70(0.47)$ & $1.48(0.51)$ \\
Height, cm $_{\text {Weight, kg }}$ & $172.3(7.91)$ & $170.3(8.42)$ & $172.3(8.88)$ \\
Education $^{b}$ & $67.4(10.8)$ & $62.2(9.3)$ & $65.1(9.9)$ \\
Estimated IQ $^{c}$ & $2.68(0.58)$ & $2.95(0.22)$ & $2.80(0.50)$ \\
GHQ & $115.1(5.15)$ & $116.1(5.06)$ & $113.1(3.13)$ \\
Impulsiveness $^{c}$ & $26.74(3.78)$ & $24.30(3.88)$ & $22.80(5.19)^{e}$ \\
Venturesomeness $^{d}$ & $8.47(5.12)$ & $10.70(4.29)$ & $12.00(4.25)^{e}$ \\
Empathy $^{d}$ & $9.26(3.19)$ & $10.65(3.08)$ & $11.84(2.25)^{e}$ \\
\hline
\end{tabular}

${ }^{a}$ Males coded as 1 , Females as 2.

${ }^{b} 1$ = GCSE, 2 = A-level; $3=$ HND + .

${ }^{c}$ Estimated from NART scores.

${ }^{d}$ IVE data was missing for 1 participant in the polydrug control group.

${ }^{e}$ Indicates a significant difference between groups at the .05 probability level.

users did not differ significantly from polydrug controls on any of these measures (see Table 7).

\section{Behavioral Measures}

Two participants did not complete the TOL test (one MDMA participant and one nondrug control). Multivariate analysis of variance of the "number of excess moves," "proportion of perfect solutions," and "subsequent thinking time per move" measures of TOL performance for the remaining 62 participants indicated that there were no significant differences between groups on any of these measures in either TOL test (see Table 9). However, there was a trend toward a significant difference in "initial thinking time" between groups for the first TOL test $[\mathrm{F}(2,59)=3.070, p=.054]$, and second TOL test $[\mathrm{F}(2,59)=3.089, p=.053]$. Post hoc analysis indicated that the initial thinking times for participants in the nondrug control group were significantly longer than those of participants in both of the other two groups (see Table 9).

Finally, analysis of the measures of MFF20 performance indicated that, although there were no group differences in the mean latencies to first response or derived "I scores," there was a marginally significant (one-tailed) difference between groups for the total number of errors committed $[\mathrm{F}(2,61)=2.696, p=.075]$. Furthermore, the difference in the total number errors committed by the polydrug and MDMA groups was significant (at the .05 significance level) $[\mathrm{F}(1,43)=5.010$, $p=.030]$, and the difference in "I scores" between these two groups was also significant at the one-tailed level $[\mathrm{F}(1,43)=3.497, p=.068]$. Post hoc analysis with Duncan's test indicated that participants in the MDMA group committed significantly more errors than participants in the polydrug control group, although they did not differ significantly from participants in the nondrug control group (see Table 9).

\section{ANALYSIS OF COMBINED DATA FROM BOTH STUDIES}

In light of the similarity of the design employed in both studies, the data for psychological measures that were common to both studies were reanalyzed using multivariate analysis with two independent factors: (1) group;

Table 8. Means (Standard Deviations) for Self-Reported Drug Consumption (Study 2)

\begin{tabular}{|c|c|c|}
\hline & $\begin{array}{c}\text { Polydrug } \\
\text { Control }\end{array}$ & $\begin{array}{l}\text { MDMA } \\
\text { Group }\end{array}$ \\
\hline \multicolumn{3}{|l|}{ Alcohol, units } \\
\hline Consumed per week & $43.25(38.2)$ & $34.94(23.3)$ \\
\hline Duration of use (years) & $8.67(4.94)$ & $7.90(2.55)$ \\
\hline \multicolumn{3}{|l|}{ Cigarettes } \\
\hline Smoked per week & $73.71(86.0)$ & $65.80(55.1)$ \\
\hline Duration of use (years) & $6.17(6.10)$ & $6.07(4.21)$ \\
\hline \multicolumn{3}{|l|}{ Cannabis, joints } \\
\hline Smoked per week & $9.31(12.1)$ & $13.74(11.6)$ \\
\hline Duration of use (years) & $5.17(5.10)$ & $6.14(2.80)$ \\
\hline \multicolumn{3}{|l|}{ Amphetamine, grams } \\
\hline Consumed per month & $1.20(3.34)$ & $1.97(3.51)$ \\
\hline Duration of use (years) & $2.65(3.88)$ & $4.46(2.52)$ \\
\hline \multicolumn{3}{|l|}{ LSD, "trips" } \\
\hline Consumed in previous year & $2.95(6.30)$ & $2.63(4.20)$ \\
\hline Duration of use (years) & $2.12(3.50)$ & $4.23(2.79)$ \\
\hline \multicolumn{3}{|l|}{ Inhalants, "hits" } \\
\hline Consumed per month & $1.13(4.46)$ & $2.50(9.08)$ \\
\hline \multicolumn{3}{|l|}{ Cocaine, grams } \\
\hline Consumed in previous year & $0.30(1.34)$ & $2.60(6.89)$ \\
\hline \multicolumn{3}{|l|}{ Psilocybin mushrooms } \\
\hline Consumed in previous year & $124(244)$ & $204(267)$ \\
\hline
\end{tabular}


Table 9. Means (Standard Deviations) for Behavioral Measures (Study 2)

\begin{tabular}{|c|c|c|c|}
\hline & $\begin{array}{c}\text { Nondrug } \\
\text { Control }(N=19)\end{array}$ & $\begin{array}{c}\text { Polydrug } \\
\text { Control }(N=20)\end{array}$ & $\operatorname{MDMA}(N=25)$ \\
\hline \multicolumn{4}{|l|}{ Tower of London test $1^{a}$} \\
\hline Number of excess moves & $1.32(0.58)$ & $1.65(0.66)$ & $1.45(0.59)$ \\
\hline Proportion perfect solns. & $65.12(13.93)$ & $56.83(14.22)$ & $57.51(13.19)$ \\
\hline Initial thinking time, ms & $3452(1609)$ & $2521(1535)$ & $2337(1401)$ \\
\hline $\begin{array}{l}\text { Subsequent thinking time, } \\
\text { ms per move }\end{array}$ & $1093(903)$ & $710(838)$ & $817(951)$ \\
\hline \multicolumn{4}{|l|}{ Matching familiar figures test } \\
\hline Latency to first response & $13.90(7.02)$ & $13.16(3.76)$ & $12.00(3.71)$ \\
\hline Total errors committed & $9.68(4.93)$ & $8.25(4.44)$ & $11.73(5.88)^{b}$ \\
\hline "I score" & $-0.28(2.20)$ & $-0.40(1.48)$ & $0.51(1.72)$ \\
\hline \multicolumn{4}{|l|}{ Tower of London test $2^{a}$} \\
\hline Number of excess moves & $1.07(0.62)$ & $1.30(0.57)$ & $1.19(0.69)$ \\
\hline Proportion perfect solns. & $68.06(15.81)$ & $62.07(13.69)$ & $65.33(15.07)$ \\
\hline Initial thinking time, ms & $3585(1858)$ & $2622(1492)$ & $2349(1582)$ \\
\hline $\begin{array}{l}\text { Subsequent thinking time, } \\
\text { ms per move }\end{array}$ & 309 (383) & $333(291)$ & $266(348)$ \\
\hline
\end{tabular}

and (2) study. Reanalysis of the data from both studies indicated that there were no significant group by study interactions for any of the measures recorded in both studies (i.e., IVE, first TOL test, and MFF20 test). There were also no significant effects of study for any of the IVE, TOL test measures, or "I score" and "mean latency to first response", MFF20 measures. There was, however, a significant difference between the number of MFF20 errors committed in Study 1 and Study 2. Participants in the two control groups in the second study committed more errors than their counterparts in the first study (see Table 10).
There was no group difference between scores on the empathy subscale of the IVE, but there were significant group differences in trait impulsiveness $[\mathrm{F}(2,105)=4.073$, $p=.020]$, and venturesomeness $[\mathrm{F}(2,105)=10.455, p<$ .001]. Post hoc analysis indicated that participants in the combined MDMA group exhibited significantly higher levels of trait impulsiveness, and participants in both of the combined groups of illicit drug-users exhibited significantly higher levels of trait venturesomeness than participants in the combined nondrug control group (See Table 10).

Table 10. Means (Standard Deviations) of Combined Data from Studies 1 and 2

\begin{tabular}{lccc}
\hline & $\begin{array}{c}\text { Nondrug } \\
\text { Control }(\mathbf{N}=\mathbf{3 5})\end{array}$ & $\begin{array}{c}\text { Polydrug } \\
\text { Control }(\mathbf{N}=\mathbf{3 2})\end{array}$ & MDMA (N= 41) \\
\hline IVE & & & \\
$\quad$ Impulsiveness & & & \\
$\quad$ Venturesomeness $^{a}$ & $8.51(4.81)$ & $10.34(4.11)$ & $11.41(4.35)^{b}$ \\
$\quad$ Empathy $^{a}$ & $8.34(3.44)$ & $10.84(3.60)$ & $11.68(2.77)^{c}$ \\
Tower of London test 1 $_{\quad}$ & $12.83(4.59)$ & $14.22(3.41)$ & $13.32(3.88)$ \\
$\quad$ Number of excess moves & $1.30(0.60)$ & $1.56(0.69)$ & $1.48(0.71)$ \\
$\quad$ Proportion perfect solns. & $63.40(14.71)$ & $58.43(15.98)$ & $58.12(16.03)$ \\
$\quad$ Initial thinking time, ms & $3562(2360)$ & $3326(2717)$ & $2776(1778)$ \\
$\quad$ Subsequent thinking time, & & & \\
$\quad$ ms per move & $1082(844)$ & $1021(1186)$ & $1115(1164)$ \\
Matching familiar figures test & & & $12.19(4.98)$ \\
$\quad$ Latency to first response & $14.95(6.51)$ & $13.75(4.37)$ & $11.76(6.48)^{c}$ \\
$\quad$ Total errors committed & $7.63(4.72)$ & $6.97(4.08)$ & $0.73(1.89)^{b}$ \\
$\quad$ "I score" & $-0.50(1.83)$ & $-0.40(1.38)$ & \\
\hline
\end{tabular}

${ }^{a}$ IVE data was missing for one participant in the polydrug control group.

${ }^{b}$ Significant difference between groups at the .05 probability level.

${ }^{c}$ Significant difference between groups at the .001 probability level. 
Multivariate analysis of variance of the "number of excess moves," "proportion of perfect solutions," "initial thinking time," and "subsequent thinking time per move" measures of TOL performance, indicated that there were no significant differences between the combined groups on any of these measures (see Table 10). The mean latencies to the first response in the MFF20 were also not significantly different between the three combined groups, but there were highly significant group differences in the number of MFF20 errors committed $[\mathrm{F}(2,105)=9.238, p<.001]$, and "I scores" [F $(2,105)=5.998, p=.003]$. Post-hoc analysis indicated that participants in the combined MDMA group committed significantly more errors, and as a result, had significantly elevated "I scores," as compared to participants in the other two groups (see Table 10).

Finally, the number of ecstasy tablets consumed by participants in the MDMA group ranged from the minimum entry requirement of 20 tablets to more than 160 . To explore the possibility of a dose-response effect on IVE and MFF20 measures of impulsivity, the MDMA group was divided into three categories: those who had taken 20 to 30 tablets of ecstasy (15 participants); those who had taken between 30 and 60 tablets (10 participants); and those who had taken more than 60 tablets (16 participants). One-way analysis of variance indicated that there was no dose-response effect for "I scores" derived from the MFF20 test, but there was a significant effect of total amount of ecstasy consumed on trait impulsiveness $[\mathrm{F}(2,38)=3.444, p=.042]$. Posthoc analysis indicated that participants in the combined MDMA group who had taken more than 30 ecstasy tablets had significantly elevated impulsiveness scores compared to participants who had only taken between 20 and 30 tablets.

\section{CORRELATIONAL ANALYSIS OF COMBINED DATA}

Correlational analysis of the combined MFF20 data indicated a highly significant negative correlation between the mean latency to the first response and the total number of errors committed in this task $[r=-0.647$, $p<$.001]. Correlational analysis between IVE, MFF20, and TOL measures revealed that, before Bonferroni correction for multiple hypothesis testing, initial thinking times in the TOL test correlated positively with the MFF20 mean latencies to first response $[r=0.210, p=$ .030], and negatively with "I scores" $[r=-0.199, p=$ $.041]$, although these correlations were not significant after such correction. Otherwise, there were no significant correlations between the IVE, MFF20, and TOL measures. In particular, IVE trait impulsiveness scores were not correlated with either the mean number of er- rors committed during, or the "I scores" derived from, the MFF20 test.

\section{DISCUSSION}

Combined data from the present studies indicated that recreational ecstasy users committed significantly more errors in the MFF20 (Cairns and Cammock 1978) than polydrug control subjects, who had similar drug histories but had never taken ecstasy, and nondrug control subjects who had never taken illicit drugs, all of whom were of similar age, height, gender, education, and estimated premorbid IQ. Although there was no significant difference in latency to first response between the three groups, the composite "I scores," which were derived by subtracting the standard score of the mean latency to first response from the standard score of the total number of errors committed $\left(Z_{e}-Z_{1}\right)$, were also significantly greater for recreational ecstasy users, than for subjects in the other two groups.

In both studies, the results of the IVE (Eysenck and Eysenck 1991) questionnaire indicated that, although there were no group differences in trait empathy scores, there were significant differences between groups in terms of venturesomeness. These differences are to be expected, however, because both groups that reported having used illicit drugs (which can be viewed as an example of venturesome behavior) reported themselves to be more venturesome than participants who reported that they had never used illicit drugs. The combined IVE data from the present studies also indicated that recreational ecstasy users exhibited elevated trait impulsiveness, as compared to participants who had never taken illicit drugs and that the recreational users who had consumed the most ecstasy exhibited the most impulsiveness.

Otherwise, the results of the present studies indicated that mood and personality measures of participants in the three groups were generally similar. In the first study, there were no significant group differences in subjective mood state at the outset of the study, state and trait anxiety measures from the STAI (Spielberger et al. 1983), or state and trait anger/hostility measures from the STAXI (Spielberger 1988). These results replicate the findings of previous studies in which we employed a similar design, (Callow 1996; Davies 1996). In the second study, however, the GHQ data revealed that participants in the MDMA group were significantly more psychologically disturbed/unhappy than participants in the nondrug control group, while GHQ for participants in the polydrug control group fell between those of the other two groups.

The cognitive performance of the three groups was also generally similar. In the first study, participants in all three groups performed equally well in the 
CANTAB spatial span task, and there were no group differences in either study in performance of the CANTAB TOL test, despite the fact that this test was repeated twice in the second study. Thus, the present results indicate that, although they were generally unimpaired on measures of mood, anxiety, anger/hostility, and $\mathrm{CANTAB}$ measures of cognitive performance, the recreational ecstasy users exhibited selective elevation of self-report and behavioral measures of impulsivity.

The present evidence that trait impulsiveness is elevated in recreational ecstasy users; whereas, self-report measures of anger/hostility did not differ between groups, is inconsistent with the findings of Ricaurte et al. (1990), who reported that their sample of 30 recreational MDMA users exhibited significantly lower scores on measures of impulsivity and indirect hostility (McCann et al. 1994). This may simply be attributable to the use of different measures, because Ricaurte et al. employed the Multidimensional Personality Questionnaire to measure impulsivity, and the Buss Durkee Hostility Inventory to measure indirect hostility. It is arguable, however, that more credence should be given to the present results. First, it should be noted that the reduction in impulsivity and indirect hostility in recreational ecstasy users reported by Ricaurte et al. was an unexpected finding. Reduced levels of serotonergic function, as indicated by low levels of 5-HIAA, have previously been found to be consistently associated with elevated levels of hostility and impulsivity (e.g., Linnoila et al. 1993); whereas, Ricaurte et al. reported the opposite. Second, we have used a design that allowed ecstasy users to be compared to a polydrug control group who had used similar quantities of other drugs and a conventional control group that had not used illicit drugs. Third, we previously found IVE trait impulsiveness to be elevated in recreational ecstasy users, accompanied by a lack of group differences between anger/hostility measures, in an earlier study in which 29 recreational ecstasy users were compared with 27 polydrug-users and 30 nondrug users (Callow 1996).

The high latency-error correlation attained for the MFF20 in the present study $[r=-0.64]$, is similar to previous reports of the MFF20 performance of nineyear olds [ $r=-0.67]$ (Cairns and Cammock 1978) and 14-year olds [ $r=-0.65]$ (Messer and Brodzinsky 1981), which suggests that is also a useful measure of adult performance. The high latency-error correlation also supported the rationale for the derivation of the "I scores," a composite index of behavioral impulsivity (Salkind and Wright 1977; Messer and Brodzinsky 1981). Thus, it is possible to interpret the significantly elevated "I scores" of participants in the combined MDMA group as evidence that the ecstasy users exhibited more impulsive behavior than participants in the two control groups.

The exact relationship between self-report measures of trait impulsiveness and behavioral measures of im- pulsivity is unclear, however, because further analysis showed that performance on these two measures was not correlated. This was not particularly surprising, however, because low correlations between self-report and behavioral measures of impulsivity have been reported by a number of previous investigators (e.g., Block et al. 1974; Gerbing et al. 1987). The lack of correlation does suggest, however, that the scores provided by these different types of measures are probably estimates of different constructs. Furthermore, Block et al. used the original MFFT to investigate the separate contribution of latency and accuracy to behavioral impulsivity in children and concluded that accuracy had important personality concomitants (inaccurate participants were characterized as more anxious, sensitive, vulnerable, structure-seeking individuals who move toward rigidity and stereotypy under conditions of stress); whereas, latency was inconsequential. Because accuracy clearly differentiated groups in the present studies, and latency did not, if high error rates on the MFF20 reflect the same personality concomitants in adults, perhaps the present results suggest that ecstasy users are more emotionally reactive and less capable of coping with high levels of cognitive demand than are individuals who have taken other illicit drugs. The latter interpretation is consistent with some of the descriptions of psychological problems that were attributed to the use of ecstasy by participants in the MDMA group in the present studies. Furthermore, although they did not differ from participants in the other two groups on CANTAB measures of cognitive performance or on self-report measures of anxiety and mood at the time of testing, at least $25 \%$ of the total sample of 41 ecstasy-using participants, reported that they believed that taking ecstasy had made them more susceptible to anxiety, depression, aggression/irritability, and mood swings, and also reduced their ability to concentrate. If high error rates on the MFF20 reflect reduced ability to cope with high levels of cognitive demand, and ecstasy causes reductions in brain serotonergic activity, the present results are also consistent with the view that 5-HT plays an orchestrating role in cognition, and that extreme deviations of 5-HT activity can result in biases in cognitive processing, which can predispose individuals to pathological conditions such as impulsive behavior, violent suicide, and aggression (Spoont 1992).

There were a number of unavoidable methodological limitations with the present studies. One was that the period of time elapsed since last use (an average of 20 days in the first study and 65 days in the second) prohibited biochemical assays of MDMA consumption. As a result, there was no objective confirmation of the dose or purity of MDMA taken. Tablets sold as "ecstasy" can contain MDA (3,4-methylenedioxyamphetamine), MDEA (3,4-ethylenedioxyethylamphetamine), or mixtures of a range of other compounds (e.g., amphetamine, caffeine, 
ephedrine, ketamine, and LSD), (Saunders 1995; Wolff et al. 1995). However, although some tablets sold as "ecstasy" contain little or no MDMA, the majority do contain MDMA, or the related compound MDEA, and because participants in the second study reported having taken an average of 50 ecstasy tablets, of which the most common were the "white dove" type, which typically contain 88 to $140 \mathrm{mg}$ of MDMA (Wolff et al. 1995), it would seem reasonable to conclude that they had, indeed, consumed a significant quantity of MDMA.

Another limitation was that, for legal and ethical reasons, there was no control over drug administration. Instead, drug consumption data had to be collected retrospectively, which inevitably created interpretative difficulties concerning the etiology of the behavioral and personality differences in recreational ecstasy users. By definition, some of the elevated trait impulsiveness, observed in both groups of participants who had used illicit drugs, probably reflects a pre-existing predisposition that may have led to subsequent use of illicit drugs. However, it is also possible that some of the elevation of trait impulsiveness, particularly the additional elevation associated with heavy past consumption of ecstasy, may be attributable to the neurotoxic effects of ecstasy on brain 5-HT systems, because, as noted above, reductions in serotonergic function have consistently been associated with elevated levels of impulsive behavior.

It is more difficult to conceive of the group difference in the MFF20 error rate as being attributable to a pre-existing trait, because this measure was markedly elevated in ecstasy-users, as compared to polydrug control subjects, and it seems implausible that only individuals with high levels of behavioral impulsivity of this type would be especially predisposed to taking ecstasy, rather than other illicit drugs. This argument is supported by the reports of the ecstasy users themselves. As indicated earlier, a number of them volunteered that their reduced ability to concentrate, impaired memory, and slowed mental processing were a direct consequence of taking ecstasy, as was their increased susceptibity to anxiety, depression, aggression/irritability, and mood swings. Clearly, however, further research, perhaps including the use of longditudinal studies, is needed to clarify this issue.

Finally, a striking feature of the present results was the selectivity of the psychological sequelae of chronic exposure to ecstasy. This is consistent with previous reports that, although the recall performance of ecstasy users was impaired, their cognitive performance was not impaired on other a variety of other neuropsychological measures (Krystal and Price 1992; Parrott 1997). It has been suggested that more general cognitive impairments associated with serotonergic denervation of the neocortex may not be evident under usual circumstances because of sufficient neural reserve (Hunter
1988). If, however, 5-HT function declines with age, ecstasy-exposed individuals could be at increased risk for developing other age-related, cognitive, and affective deficits. Further research with older ecstasy users and young participants who have not used ecstasy for more extended periods of time, is needed to clarify the longerterm clinical implications of the present findings.

\section{ACKNOWLEDGMENTS}

The author thanks Gareth Davies, Clare Edwards, Richard Green, Laura Grundy, Joanne Hughes, Rachel Hunter, and Alison Kewell for their contribution to the recruitment and assessment of participants.

\section{REFERENCES}

Baddeley A (1990): Human Memory: Theory and Practice. Boston, Allyn \& Bacon, Inc

Block J, Block JH, Harrington DM (1974): Some misgivings about the Matching Familiar Figures Test as a measure of reflection impulsivity. Child Devel 47:218-226

Callow N (1996): Use of the "snowballing" technique to investigate subjective mood and personality traits associated with "ecstasy." Proceed Brit Psych Soc 4:65

Cairns E, Cammock T (1978): Development of a more reliable version of the Matching Familiar Figures Test. Dev Psychol 13:555-560

Curran HV, Travill RA (1997): Mood and cognitive effects of 3,4-methylenedioxymethamphetamine (MDMA, "ecstasy"): Weekend "high" followed by mid-week low. Addiction 92:821-831

Davies G (1996): Investigation of subjective mood and personality traits associated with recreational use of "ecstasy." Proceed Brit Psych Soc 4:65

Delgado L, Charney DS, Price LH, Aghajanian GK, Landis H, Heninger GR (1990): Serotonin function and the mechanism of antidepressant action: Reversal of antidepressant-induced remission by rapid depletion of plasma tryptophan. Arch Gen Psychiat 47:411-418

Eysenck HJ, Eysenck SBG (1991): Adult Impulsiveness, Venturesomeness, and Empathy Scale. London, UK, Hodder \& Stoughton, Ltd

Frederick D, Paule M (1997): Effects of MDMA on complex brain function in laboratory animals. Neurosci Biobehav Rev 21:67-78

Garvey MJ, Noyes R, Woodman C, Laukes C (1995): Relationship of generalized anxiety symptoms to urinary 5-hydroxyindoleacetic acid and vanillylmandelic acid. Psychiat Res 57:1-5

Gerbing DW, Ahadi SA, Patton JH (1987): Toward a conceptualization of impulsivity: Components across the behavioral and self-report domains. Multivariate Behav Res 22:357-379

Goldberg D (1978): General Health Questionnaire. Windsor, UK, NFER-Nelson Publishing Company, Ltd 
Green AR, Cross AJ, Goodwin GM (1995): Review of the pharmacology and clinical pharmacology of 3,4-methylenedioxymethamphetamine (MDMA or ecstasy). Psychopharmacology 119:247-260

Hunter A (1988): Serotonergic involvement in learning and memory. Biochem Soc Trans 17:79-81

Kagan J, Rosman BL, Day D, Albert J, Phillips W (1964): Information processing in the child: Significance of analytic and reflective attitudes. Psychol Mono 78(1, Whole No. 587)

Krystal JA, Price LH (1992): Chronic 3,4-methylenedioxymethamphetamine (MDMA) use: Effects on mood and neuropsychological function. J Drug Alcohol Abuse 18:331-341

Linnoila M, Virkkunen M, George T, Higley D (1993): Impulse control disorders. Int Clin Psychopharm 8:53-56

McCann UD, Ridenour A, Shaman Y, Ricuarte GA (1994): Serotonin neurotoxicity after MDMA ("ecstasy"): A controlled study in humans. Neuropsychopharmacology 10:129-138

McKenna DJ, Peroutka SJ (1990): Neurochemistry and neurotoxicity of 3,4 methylene-dioxymethamphetamine (MDMA; ecstasy). J Neurochemistry 54:14-22

Messer SB, Brodzinsky DM (1981): Three year stability of reflection-impulsivity in young adolescents. Dev Psychol 17:848-850

Nelson H (1982): National Adult Reading Test, Windsor, UK, NFER-Nelson Publishing Company, Ltd

Owen AM, Downes JJ, Sahakian BJ, Polkey CE, Robbins TW (1990): Planning and spatial working memory following frontal lobe lesions in man. Neuropsychologia 28:10211034

Parrott AC (1997): MDMA, mood, and memory: The agnosia of the ecstasy. Brit Psych Soc Proc 5:49

Ricaurte GA, Finnegan KT, Irwin I, Langston JW (1990): Aminergic metabolites in cerebrospinal fluid of humans previously exposed to MDMA: Preliminary observations. Ann NY Ac Sci 600:699-710

Salkind NJ, Wright J (1977): The development of reflection- impulsivity and cognitive efficiency: An integrated model. Human Dev 20:377-387

Saunders N (1995): Ecstasy and the Dance Culture. London, UK, Neal's Yard Publishing

Shallice T (1982): Specific impairments in planning. Phil Trans R Soc Lond B2948:199-209

Smith SE, Pihl RO, Young SW, Ervin FR (1987): A test of possible cognitive and environmental influences on the mood lowering effect of tryptophan depletion in normal males. Psychopharmacology 91:451-457

Spielberger CD (1988): State-Trait Anger Expression Inventory. Odessa, FL, Psychological Assessment Resources, Inc

Spielberger CD, Gorsuch RL, Lushene R, Vagg PR, Jacobs GA (1983): Self-Evaluation Questionnaire. Palo Alto, CA, Consulting Psychologists Press Inc

Spoont MR (1992): Modulatory role of serotonin in neural information processing: Implications for human psychopathology. Psych Bull 112:330-350

Steele TD, McCann UD, Ricuarte GA (1994): 3,4-Methylenedioxymethamphetamine (MDMA, "ecstasy"): Pharmacology and toxicology in animals and humans. Addiction 89:539-551

Szabo Z, Scheffel U, McCann U, Dannals RF, Ravert HT, Mathews WB, Musachio JL, Ricaurte GA (1997): Reductions of 5-HT transporters in MDMA users observed using PET with [C-11]\{+\}McN5652. Soc Neurosci Abstr 123:2-23

Traskman-Bendz L, Asberg M, Schalling D (1986): Serotonergic function and suicidal behavior in personality disorders. Ann NY Ac Sci 487:168-174

Wilson B, Cockburn J, Baddeley A (1985): The Rivermead Behavioural Memory Test. Thames Valley Text Co, Reading, UK

Wolff K, Hay AWM, Sherlock K, Conner M (1995): Contents of "ecstasy." Lancet 346:1100-1101

Young SW, Smith SE, Pihl RO, Ervin FR (1985): Tryptophan depletion causes rapid lowering of mood in normal males. Psychopharmacology 87:173-177 